\title{
Erratum
}

\section{Imbalance in the composition of the duodenal microbiota of children with coeliac disease}

Inmaculada Nadal, Ester Donat, Carmen Ribes-Koninckx, Miguel Calabuig and Yolanda Sanz

Journal of Medical Microbiology (2007), 56, part 12, 1669-1674

The name of the second author was spelt incorrectly; it should be spelt Ester Donat. 